\title{
Frequência e duração das ações manipulativas no ato de brincar com cubos em crianças com baixa visão
}

\section{Frequency and duration of manipulative actions in the act of playing with cubes in children with low vision}

\section{Frecuencia y duración de las acciones manipulativas en el acto de jugar con cubos en niños con baja visión}

Recebido: 06/12/2019

Aprovado: 05/07/2020

Publicado: 03/03/2021

\section{Nathalia Quintino Pereira Silva ${ }^{1}$ Caroline de Oliveira ${ }^{2}$ Paula Berteli Pelizaro ${ }^{3}$ Karina Pereira ${ }^{4}$}

Trata-se de um estudo transversal/ observacional, com o objetivo de analisar a frequência e o tempo de permanência das ações manipulativas em crianças ao explorar cubos de diferentes estímulos sensoriais (estímulo luminoso, auditivo, tátil, de alto contraste, transparente e preto). Foram avaliadas sete crianças com baixa visão e sete sem baixa visão $(8,8$ anos $\pm 1,02)$. As crianças foram filmadas durante $o$ ato de brincar com os cubos. No grupo I, houve diferença significativa nos cubos de alto contraste $(\mathrm{p}=0,031)$ e tátil $(\mathrm{p}=0,017)$ para a ação manipulativa de agitar o cubo. No grupo II, o resultado significativo ocorreu na ação de girar $(\mathrm{p}=0,047)$ o cubo luminoso e na ação de retirar as mãos $(\mathrm{p}=0,006)$ no cubo tátil. Não houve diferença na média geral da frequência e no tempo de manipulação dos cubos. Os cubos com estímulos tátil e de alto contraste foram favoráveis para estimular crianças com baixa visão dos 7 aos 10 anos de idade.

Descritores: Baixa visão; Desenvolvimento infantil; Destreza motora.

This is a cross-sectional/observational study. It aimed to analyze the frequency and duration of manipulative actions of children when exploring cubes of different sensory stimuli (light, auditory, tactile, high-contrast, transparent and black). Seven children with low vision and seven with normal vision (8.8 years \pm 1.02 ) were evaluated. The children were filmed during the act of playing with the cubes. For the group I, there was a significant difference in the high contrast $(p=0.031)$ and tactile ( $p=0.017)$ cubes for the manipulative action of shaking the cube. For the group II, significant results occurred in the action of turning $(p=0.047)$ the luminous cube and in the action of removing hands $(p=0.006)$ in the tactile cube. There was no difference in the general average of frequency and manipulation time of the cubes. The cubes with tactile and high contrast stimuli were favorable to stimulate children with low vision from 7 to 10 years of age.

Descriptors: Vision, Low; Child development; Motor skills.

Se trata de un estudio transversal/observacional, con el objetivo de analizar la frecuencia y la duración de las acciones manipulativas en los niños al explorar cubos de diferentes estímulos sensoriales (estímulo luminoso, auditivo, táctil, de alto contraste, transparente y negro). Se evaluaron siete niños con baja visión y siete sin baja visión $(8,8$ años $\pm 1,02)$. Los niños fueron filmados mientras jugaban con los cubos. En el Grupo I, hubo una diferencia significativa en los cubos de alto contraste $(\mathrm{p}=0,031)$ y táctil $(\mathrm{p}=0,017)$ para la acción manipulativa de agitar el cubo. En el Grupo II el resultado significativo fue en la acción de girar $(p=0,047)$ el cubo luminoso y en la acción de quitar las manos $(\mathrm{p}=0,006)$ del cubo táctil. No hubo diferencias en la frecuencia y el tiempo medio de manipulación de los cubos. Los cubos con estímulos táctil y de alto contraste fueron favorables para estimular a los niños con baja visión de 7 a 10 años.

Descriptores: Baja visión; Desarrollo infantil; Destreza motora.

1. Fisioterapeuta. Mestranda em Fisioterapia pela Universidade Federal do Triângulo Mineiro (UFTM), Uberaba, MG, Brasil. ORCID: 0000-0001-8771-3158 E-mail: nath_quintino@hotmail.com

2. Fisioterapeuta. Residente Multiprofissional em Atenção Integral a Saúde, Uberaba, MG, Brasil. ORCID: 0000-0002-6225-823X E-mail: karollolive@hotmail.com

3. Fisioterapeuta. Mestranda em Fisioterapia pela UFTM, Uberaba, MG, Brasil. ORCID: 0000-0001-5313-8968 E-mail: paulabertelip@hotmail.com

4. Fisioterapeuta. Especialista em Intervenção em Neuropediatria. Mestre e Doutora em Fisioterapia. Professora Associada do Programa de Pós-Graduação em Fisioterapia da Universidade Federal do Triângulo Mineiro (UFTM), Uberaba, MG, Brasil. ORCID: 0000-0001-7486-1004 E-mail: karina.pereira@uftm.edu.br 


\section{INTRODUÇÃO}

$\mathbf{0}$

brincar pode ser definido como uma ação espontânea, comandada e controlada pela criança, constituída por flexibilidade e prazer, permitindo novas combinações de ideias e comportamentos ${ }^{1}$. Com o brincar a criança tem a possibilidade de expor suas emoções, dominar impulsos, crescer o seu campo de experiências e contato social ${ }^{2}$, uma vez que auxilia no desenvolvimento e aprimoramento dos movimentos corporais que são denominados e agrupados em um conjunto chamado de ações motoras ${ }^{3}$.

A funcionalidade e a independência da criança estão intimamente relacionadas com o desenvolvimento motor e com as habilidades manipulativas adquiridas ao longo de sua evolução ${ }^{4}$. 0 ato de brincar possibilita à criança aprimorar as ações manipulativas que já faz parte do seu repertório motor e adquirir novas ações, por meio de experiências e do contato com diferentes objetos, ampliando seu leque de movimentos ${ }^{5}$.

As crianças com deficiência visual podem, em alguns casos, não apresentar motivação suficiente para explorar o meio que a rodeia, devido à falta de estimulação adequada, causando atrasos no desenvolvimento motor e na aquisição de sua independência ${ }^{6} .0$ ato de brincar pode ser utilizado como ferramenta de estimulação, uma vez que a brincadeira se constitui em ações naturais de imaginação e espontaneidade 7 . Outro elemento que pode ou não estar inserido no ato de brincar, e que contribui significativamente para a estimulação e desenvolvimento da criança com deficiência visual, é o brinquedo. Esse objeto é constituído por variáveis características físicas ou sensoriais, que contribui para estimular a criança possibilitando maior exploração do meio, aprimorando e adquirindo novas habilidades ${ }^{8}$.

$\mathrm{Na}$ estimulação de crianças com deficiência visual, deve-se utilizar estímulos que trabalhem com outros sentidos remanescentes, além dos resquícios visuais da criança ${ }^{9}$. Um dos sentidos que auxilia a criança na exploração do ambiente é o tato e as propriedades físicas dos objetos (como cubos grandes), que permite gerar resultados positivos na aquisição e no aprimoramento de ações motoras ${ }^{3}$.

Cerca de 1,4 milhões de crianças apresentam deficiência visual no mundo. Desse total, 90\% são de países em desenvolvimento ${ }^{10}$; e 20\% dos escolares apresentam algum distúrbio vinculado à visão com etiologia biológica, social ou ambiental ${ }^{11}$. Na infância, o sistema ocular e as vias de condução dos impulsos visuais apresentam-se em desenvolvimento, e a sensibilidade relacionada ao contraste encontra-se em avançado aperfeiçoamento. A partir dos 2 anos de idade, a mielinização do nervo óptico está completa ${ }^{12}$. Durante o desenvolvimento, é necessário avaliar as reações perceptivo-visuais que vão resultar em uma resposta visomotora às possíveis reações (fixação, seguimento, exploração), nas quais sofrem mudanças e adaptações conforme a idade cronológica de cada criança10.

Um estudo com crianças de 3 anos de idade mostrou a frequência das ações motoras de crianças com baixa visão e visão normal por meio da análise da manipulação de cubos com estímulos visuais (luminoso e alto-contraste) e sem estímulos visuais (transparente e preto). As autoras verificaram que o cubo de alto-contraste estimulou as crianças com baixa visão a realizarem mais ações motoras, como o alcance bimanual e o girar o cubo. E identificaram semelhança nas ações motoras entre as crianças com e sem baixa visão, mostrando que as mesmas são capazes de interagir com o meio externo ${ }^{3}$.

0 objetivo do presente estudo foi analisar a frequência e o tempo de permanência das ações manipulativas em crianças ao explorar cubos de diferentes estímulos sensoriais (estímulo luminoso, auditivo, tátil, de alto contraste, transparente e preto).

\section{MÉTODO}

Trata-se de um estudo transversal e observacional, realizado em 2019 com crianças de 7 a 10 anos, na cidade de Uberaba. 0 estudo foi aprovado pelo Comitê de Ética da Universidade Federal do Triângulo Mineiro (2.694.915/2018). 
Os critérios de inclusão para o grupo com baixa visão (grupo I) foram: ambos os sexos, na faixa etária de 7 a 10 anos, diagnóstico oftalmológico de baixa visão e nenhuma outra condição de incapacidade associada (deficiência intelectual, neurológica, ortopédica, surdez e histórico de crises convulsivas), frequentadoras de instituições especializadas em pessoas com deficiência visual e autorização dos pais ou responsáveis para participar do estudo. Devido à dificuldade de conseguir uma amostra homogênea, as crianças com baixa visão foram selecionadas por conveniência. 0 grupo sem baixa visão (grupo II) foi composto por crianças sem alteração neurológica, ortopédica, sensorial e cognitiva, (especialmente sem alterações visuais) de ambos os sexos, na faixa etária de 7 a 10 anos, com o consentimento dos pais ou responsáveis e recrutadas por sorteio em uma escola estadual local, assegurando-se o pareamento por idade e sexo.

Esta pesquisa adotou a metodologia realizada no estudo de Schmitt \& Pereira (2014, 2016) ${ }^{3}$, no qual foram caracterizadas e quantificadas as ações motoras de crianças com baixa visão, dos 3 anos aos 3 anos e 10 meses, sendo necessário realizar adaptações com base no novo perfil antropométrico das crianças do presente estudo.

Durante a avaliação, foram utilizados cubos com as seguintes especificações: 6 cubos (15cm x 15cm e 410g) (Figura 1): (A) cubo de acrílico (transparente); (B) cubo sem contraste (cor preta); (C) cubo com diferentes estímulo de alto contraste em branco e preto; (D) cubo com estímulo luminoso no interior, duas das faces opostas foram revestidas com material transparente e as demais nas cores amarelo, azul, verde e vermelho; (E) cubo com estímulo auditivo, com a presença de guizo e revestido de papel cinza claro em seu interior e (F) cubo com estímulo tátil, apresentando em cada uma das seis faces uma textura de diferentes materiais, dentre eles: macio, ondulado (pequeno e maior), áspero e rugoso.

Figura 1. Representação dos cubos. Uberaba, 2020.

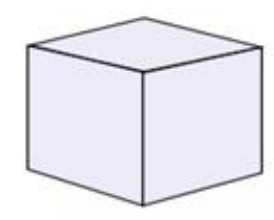

A

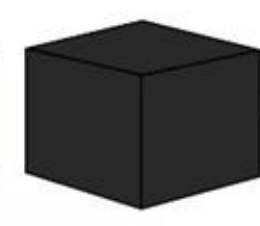

B

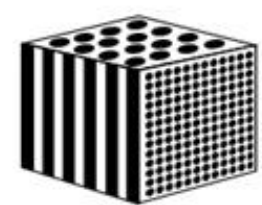

C

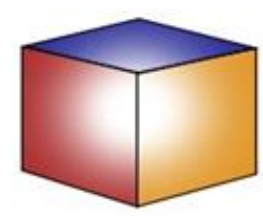

D

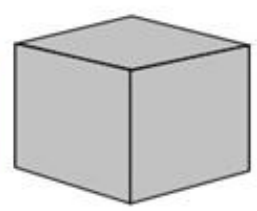

$\mathbf{E}$

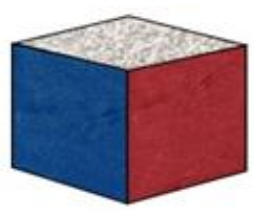

$\mathbf{F}$

Legenda: A: cubo transparente; B: cubo preto; C: cubo alto-contraste; D: cubo luminoso; E: cubo auditivo; F: cubo tátil Fonte: Oliveira C, Silva PQN, Pelizaro BP, Pereira K, $2020^{14}$.

Duas câmeras digitais foram utilizadas para registrar as ações manipulativas das crianças durante o brincar com os cubos. Uma câmara Samsung ${ }^{\circledR}$ (DVD SC-DX 103) foi posicionada sobre um tripé (PowerPack - trip 21) e uma câmera GoPro ${ }^{\circledR}$ Hero 3+ Black posicionada lateralmente, permitindo visualizar toda a avaliação. A padronização de altura, distância e angulações foi determinada mediante um estudo piloto permitindo adequar as medidas de acordo com o perfil antropométrico das crianças. Além disso, utilizou-se dois tatames emborrachados quadrados (1m x $1 \mathrm{~m} \times 3 \mathrm{~cm})$ e um cronômetro digital.

A coleta foi realizada nos meses de abril e maio de 2019, por um avaliador treinado e orientado, em salas com condições harmoniosas de iluminação, temperatura e ruídos. A cada avaliação, os seis cubos eram randomizados em estimulo sensorial e face para ser disponibilizado a cada criança, sendo estes organizados e posicionados ao lado do avaliador para facilitar durante a ordem de entrega a criança.

No início da avaliação, o avaliador interagia com a criança perguntando sobre suas brincadeiras e brinquedos favoritos, com vistas a tranquilizá-la e promover uma avaliação 
agradável. Durante a avaliação, a criança deveria sentar com as pernas cruzadas em frente ao avaliador para que os cubos fossem entregues sobre o tatame na região medial da criança. Cada cubo foi disponibilizado à criança por 40 segundos, sendo o intervalo entre a entrega de um cubo e outro de 10 segundos. Nos primeiros segundos foi aplicado um comando verbal para estimular a criança a explorar o cubo: Vamos conhecer esse brinquedo? Esse mesmo procedimento foi realizado com todos os cubos.

As filmagens foram analisadas por meio do programa BSPlayer Profile. Em um primeiro momento, foi reduzida a velocidade em $70 \%$ abaixo da velocidade normal, para facilitar a identificação das ações manipulativas realizadas pelas crianças em cada um dos cubos. Em seguida, voltou para a velocidade normal para calcular o tempo que a criança permanecia manipulando o cubo, sendo que esse tempo foi calculado dentro dos 40 segundos já estabelecidos, não havendo contabilidade em milésimos.

As ações motoras contabilizadas em cada cubo fazem parte de dois estudos ${ }^{13,14}$. As novas ações apresentadas no estudo: Ações manipulativas e o ato de criar brincadeiras com cubos em crianças com e sem baixa visão, estão na tabela abaixo (Quadro 1).

Quadro 1. Ações manipulativas e os conceitos das ações realizadas pelas crianças de ambos os grupos. Uberaba, 2020.

\begin{tabular}{|l|l|}
\hline \multicolumn{1}{|c|}{ Ações manipulativas } & \multicolumn{1}{c|}{ Conceitos } \\
\hline Apoiar o cubo em uma das arestas & $\begin{array}{l}\text { Movimento de rotação do cubo permanecendo em apenas uma aresta } \\
\text { do cubo }\end{array}$ \\
\hline Aproximar os olhos ao cubo & Movimento de aproximar os olhos em direção ao cubo \\
\hline Segurar o cubo com apenas uma mão & $\begin{array}{l}\text { Movimento de apoiar um cubo, sem que este tenha contato com o } \\
\text { solo, com apenas uma mão }\end{array}$ \\
\hline Encostar o rosto no cubo & Movimento de aproximar o rosto ao cubo com o intuito de encostar \\
\hline
\end{tabular}
Fonte: Oliveira C et al. ${ }^{14}$

As variáveis dependentes do estudo foram frequência das ações motoras e o tempo de permanência com determinado cubo; as variáveis independentes: grupo de baixa visão e visão normal; e as variáveis moderadoras: cubos com estimulo visual (alto-contraste e luminoso, tátil, auditivo) e sem estímulo visual (transparente e preto).

Para realizar a análise dos dados foi utilizada a ferramenta Statistical Package for the Social Sciences (SPSS ${ }^{\circledR} 20.0$ ), considerando o nível de significância de $5 \%$ ( $\left.\leq \leq 0,05\right)$. Os dados para verificar a frequência das ações manipulativas por cubo foram apresentados de forma descritiva: mediana de tendência central (media e mediana) e dispersão (desvio padrão, medida de dispersão - mínimo e máximo), frequência absoluta e relativa.

0 teste de normalidade Shapiro-Wilk foi aplicado para verificar a distribuição dos dados e não foi aceita a hipótese de normalidade para todas as variáveis, desta forma para algumas variáveis foi utilizado o teste $t$ (com normalidade) e em outras o teste Mann-Whitney (sem normalidade) para comparar os resultados da frequência das ações motoras entre os cubos e grupos.

\section{RESULTADOS}

Participaram do estudo 14 crianças, sendo sete com diagnóstico clínico de baixa visão e sete sem baixa visão $(8,8$ anos $\pm 1,02)$.

Em relação à média da frequência das ações manipulativas em cada cubo, pelas crianças, não se obteve diferença significativa entre o grupo I e o grupo II. Porém, é possível observar que o cubo tátil e alto-contraste se destacaram em relação aos demais, no grupo I (figura 2). 
Figura 2. Frequências das ações motoras realizadas pelas crianças em cada cubo. Uberaba, 2019.

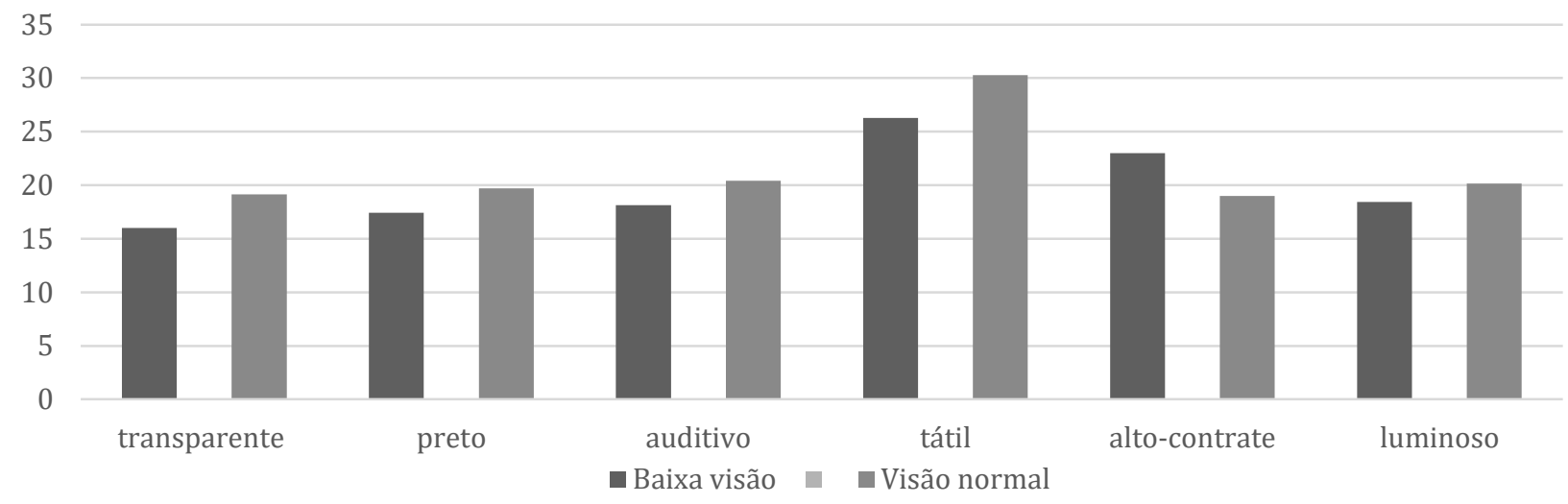

Quanto à frequência de cada ação manipulativa nos cubos, houve diferença significativa no grupo I para a ação manipulativa de agitar no cubo de alto-contraste $(p=0,031)$ e no cubo tátil $(\mathrm{p}=0,017)$. Em relação ao grupo II, o resultado significativo ocorreu na ação de girar $(\mathrm{p}=0,047)$ o cubo luminoso e na ação de retirar as mãos $(\mathrm{p}=0,006)$ no cubo tátil (Tabela 1$)$.

Ao se analisar a média do tempo de permanência de cada cubo em segundos pelas crianças (Figura 3) não foi possível eleger uma diferença significativa entre o grupo I e o grupo II. 
Tabela 1. Frequência das ações motoras realizadas pelos Grupos I e II nos quatro cubos. Uberaba, 2019.

\begin{tabular}{|c|c|c|c|c|c|c|c|c|c|c|c|c|c|c|c|c|c|c|}
\hline Cubos & Grupos & Freq & Afastar & Agitar & $\begin{array}{c}\text { Alcance } \\
\text { Bimanual }\end{array}$ & $\begin{array}{c}\text { Alcance } \\
\text { Unimanual }\end{array}$ & Aproximar & $\begin{array}{l}\text { Bater } \\
\text { c/o } \\
\text { cubo }\end{array}$ & $\begin{array}{c}\text { Bater } \\
\text { no } \\
\text { cubo }\end{array}$ & Deslizar & Girar & Jogar & $\begin{array}{l}\text { Apoiar } \\
\text { uma } \\
\text { aresta }\end{array}$ & $\begin{array}{l}\text { Retirar } \\
\text { uma } \\
\text { mão }\end{array}$ & $\begin{array}{l}\text { Aprox. } \\
\text { os } \\
\text { olhos } \\
\text { do } \\
\text { cubo }\end{array}$ & $\begin{array}{l}\text { Segurar } \\
\text { com } \\
\text { uma } \\
\text { mão }\end{array}$ & $\begin{array}{c}\text { Encostar } \\
\text { o } \\
\text { cotovelo } \\
\text { no cubo }\end{array}$ & $\begin{array}{l}\text { Encostar } \\
\text { no rosto }\end{array}$ \\
\hline \multirow{6}{*}{ 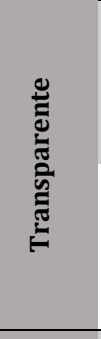 } & \multirow{3}{*}{ I } & $\begin{array}{l}\text { Min; } \\
\text { Máx }\end{array}$ & $0 ; 1$ & $0 ; 2$ & $0 ; 3$ & $0 ; 1$ & $0 ; 4$ & & $0 ; 3$ & $0 ; 1$ & $2 ; 10$ & $0 ; 3$ & $1 ; 6$ & $0 ; 2$ & $0 ; 1$ & $0 ; 1$ & . & . \\
\hline & & Med & 0,43 & 0,96 & 1,14 & 0,29 & 2,29 & . & 0,86 & 0,29 & 5,29 & 0,57 & 3,14 & 0,57 & 0,14 & 0,14 & . & . \\
\hline & & $\mathrm{p}$ & 0,827 & & 0,297 & & 0,684 & & 0,872 & 0,872 & 0,058 & 0,476 & 0,823 & 0,37 & 1 & 0,476 & . & . \\
\hline & \multirow{3}{*}{ II } & $\begin{array}{l}\text { Min; } \\
\text { Máx }\end{array}$ & $0 ; 2$ & . & $1 ; 4$ & . & $0 ; 6$ & . & $0 ; 5$ & $0 ; 2$ & $5 ; 15$ & $0 ; 1$ & $0 ; 7$ & $0 ; 3$ & $0 ; 1$ & $0 ; 2$ & . & . \\
\hline & & Med & 0,57 & . & 1,71 & . & 1,86 & . & 1,14 & 0,43 & 8,71 & 0,14 & 2,86 & 1,14 & 0,14 & 0,43 & . & . \\
\hline & & $\mathrm{p}$ & 0,827 & . & 0,297 & . & 0,684 & & 0,872 & 0,872 & 0,058 & 0,476 & 0,823 & 0,37 & 1 & 0,476 & . & . \\
\hline \multirow{6}{*}{ 总 } & \multirow{3}{*}{ I } & $\begin{array}{l}\text { Min; } \\
\text { Máx }\end{array}$ & $0 ; 1$ & $0 ; 3$ & $1 ; 2$ & $0 ; 1$ & $0 ; 3$ & $0 ; 1$ & . & $0 ; 2$ & $0 ; 16$ & . & . & $0 ; 1$ & . & $0 ; 4$ & . & . \\
\hline & & Med & 0,14 & 1,14 & 1,14 & 0,14 & 0,71 & 0,14 & 2,14 & 0,71 & 7,51 & 0,86 & 2 & 0,14 & . & 0,57 & . & . \\
\hline & & $\mathrm{p}$ & 0,53 & 0,08 & 0,476 & 0,53 & & & 0,831 & 0,943 & 0,601 & . & 0,236 & 0,073 & 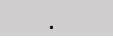 & 0,656 & . & . \\
\hline & \multirow{3}{*}{ II } & $\begin{array}{l}\text { Min; } \\
\text { Máx }\end{array}$ & $0 ; 1$ & $0 ; 1$ & 1,3 & $0 ; 1$ & . & · & $0 ; 5$ & $0 ; 9$ & $4 ; 13$ & . & $0 ; 9$ & $0 ; 5$ & . & $0 ; 1$ & . & . \\
\hline & & Med & 0,29 & 0,29 & 1,43 & 0,29 & . & . & 1,43 & 1,57 & 9 & . & 3,71 & 1,43 & . & 0,29 & . & . \\
\hline & & $\mathrm{p}$ & 0,53 & 0,08 & 0,476 & 0,53 & . & . & 0,831 & 0,943 & 0,601 &. & 0,236 & 0,073 & . & 0,656 &. & . \\
\hline \multirow{6}{*}{ 总 } & \multirow{3}{*}{ I } & $\begin{array}{l}\text { Min; } \\
\text { Máx }\end{array}$ & $0 ; 1$ & $0 ; 1$ & $1 ; 2$ & $0 ; 2$ & $0 ; 7$ & & $0 ; 2$ & $0 ; 3$ & $4 ; 9$ & . & $0 ; 10$ & $0 ; 2$ & $0 ; 4$ & $0 ; 2$ & . & . \\
\hline & & Med & 0,14 & 0,29 & 1,29 & 0,29 & 3 & . & 0,57 & 0,86 & 6,57 & . & 3,71 & 0,57 & 0,86 & 0,29 & . & . \\
\hline & & $\mathrm{p}$ & 1 & . & 0,496 & & 0,054 & & 0,656 & 0,748 & 0,047 & . & 0,445 & 0,393 & 0,943 & 0,593 & . & . \\
\hline & \multirow{3}{*}{ II } & $\begin{array}{l}\text { Min; } \\
\text { Máx }\end{array}$ & $0 ; 1$ & . & $1 ; 3$ & . & $0 ; 2$ & & $0 ; 4$ & $0 ; 2$ & 6;14 & . & $2 ; 9$ & $0 ; 4$ & $0 ; 2$ & $0 ; 2$ & . & . \\
\hline & & Med & 0,14 & . & 1,57 & . & 0,71 & . & 0,57 & 0,43 & 9,57 & . & 5 & 1,14 & 0,57 & 0,43 & . & . \\
\hline & & $\mathrm{p}$ & 1 & . & 0,496 &. & 0,054 &. & 0,656 & 0,748 & $0,047^{*}$ & . & 0,445 & 0,393 & 0,943 & 0,593 &. &. \\
\hline \multirow{6}{*}{ 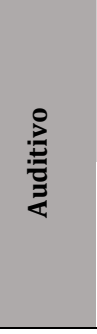 } & \multirow{3}{*}{ I } & $\begin{array}{l}\text { Min; } \\
\text { Máx }\end{array}$ & . & $0 ; 10$ & $1 ; 2$ & $0 ; 1$ & $3 ; 0$ & & $0 ; 4$ & $0 ; 2$ & $0 ; 19$ & $0 ; 1$ & $0 ; 5$ & $0 ; 2$ & . & . & . & . \\
\hline & & Med & & 3,49 & 0,37 & 0,48 & 1,34 & & 1,43 & 0,57 & 8,57 & 0,14 & 1,43 & 0,71 & . & . & . & . \\
\hline & & $\mathrm{p}$ & & 0,948 & 0,5 & 0,656 & 0,782 & & 0,378 & 0,496 & 0,483 & . & 1 & 0,784 & & . & . & . \\
\hline & \multirow{3}{*}{ II } & $\begin{array}{l}\text { Min; } \\
\text { Máx }\end{array}$ & $0 ; 1$ & $0 ; 7$ & $0 ; 3$ & $0 ; 2$ & $0 ; 2$ & & $0 ; 7$ & $0 ; 1$ & $5 ; 17$ & . & $0 ; 4$ & $0 ; 4$ & . & . & . & . \\
\hline & & Med & 0,14 & 2,43 & 1,43 & 0,29 & 1 & . & 1 & 0,29 & 10,86 & . & 1,71 & 1,29 & . & . & . & . \\
\hline & & $\mathrm{p}$ & . & 0,948 & 0,5 & 0,656 & 0,782 & . & 0,378 & 0,496 & 0,483 & . & 1 & 0,784 & . & . & . & . \\
\hline
\end{tabular}




\begin{tabular}{|c|c|c|c|c|c|c|c|c|c|c|c|c|c|c|c|c|}
\hline \multirow{6}{*}{ 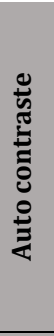 } & \multirow{3}{*}{ I } & $\begin{array}{l}\text { Min; } \\
\text { Máx }\end{array}$ & $0 ; 1$ & $0 ; 2$ & $1 ; 3$ & $0 ; 1$ & $0 ; 5$ & $0 ; 6$ & $0 ; 1$ & $5 ; 16$ & $0 ; 9$ & $0 ; 10$ & $0 ; 3$ & $0 ; 1$ & $0 ; 1$ & . \\
\hline & & Med & 0,29 & 1 & 1,29 & 0,14 & 1,57 & 1,71 & 0,43 & 10,29 & 1,57 & 3,86 & 0,43 & 0,14 & 0,29 & . \\
\hline & & $\mathrm{p}$ & 1 & $0,031 *$ & 0,593 & 0,917 & 0,08 & 0,173 & 0,521 & 1 & & 0,399 & 0,199 & 0,423 & 0,656 & . \\
\hline & \multirow{3}{*}{ II } & $\begin{array}{l}\text { Min; } \\
\text { Máx }\end{array}$ & $0 ; 1$ & $0 ; 1$ & $1 ; 3$ & $0 ; 2$ & $0 ; 1$ & $0 ; 2$ & $0 ; 4$ & $5 ; 15$ & . & $0 ; 7$ & $0 ; 1$ & $0 ; 2$ & $0 ; 5$ & . \\
\hline & & Med & 0,29 & 0,14 & 1,43 & 0,29 & 0,29 & 0,29 & 1,43 & 10,29 & . & 2,71 & 0,57 & 0,57 & 0,71 & . \\
\hline & & $\mathrm{p}$ & 1 & 0,031 & 0,593 & 0,917 & 0,08 & 0,173 & 0,521 & 1 & . & 0,399 & 0,199 & 0,423 & 0,656 & . \\
\hline \multirow{5}{*}{ 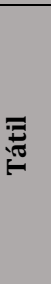 } & \multirow{3}{*}{ I } & $\begin{array}{l}\text { Min; } \\
\text { Máx }\end{array}$ & $0 ; 1$ & $0 ; 4$ & $1 ; 3$ & $0 ; 12$ & $0 ; 2$ & . & $1 ; 15$ & $4 ; 22$ & $0 ; 13$ & $0 ; 3$ & $0 ; 1$ & $0 ; 1$ & $0 ; 2$ & . \\
\hline & & Med & 0,14 & 2 & 1,57 & 2,43 & 0,43 & . & 6,29 & 8,57 & 3,71 & 0,43 & 0,14 & 0,14 & 0,43 & . \\
\hline & & $\mathrm{p}$ & 0,53 & 0,017 * & 0,218 & 0,424 & 0,476 & . & 0,297 & 0,084 & 0,2 & 0,262 & 0,006 * & 0,53 & 0,657 & . \\
\hline & \multirow[t]{2}{*}{ II } & $\begin{array}{l}\text { Min; } \\
\text { Máx }\end{array}$ & $0 ; 1$ & $0 ; 1$ & $1 ; 3$ & $0 ; 1$ & $0 ; 1$ & $0 ; 21$ & $0 ; 7$ & $6 ; 26$ & $0 ; 1$ & $0 ; 7$ & $0 ; 3$ & $0 ; 1$ & $0 ; 3$ & $0 ; 1$ \\
\hline & & Med & 0,29 & 0,43 & 2 & 0,14 & 0,14 & 4,86 & 4,14 & 13,71 & 0,14 & 1,71 & 1,86 & 0,29 & 0,43 & 0,14 \\
\hline
\end{tabular}

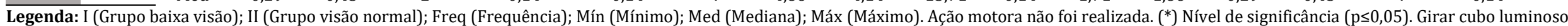
$(\mathrm{p}=0,047)$, agitar cubo alto-contraste $(\mathrm{p}=0,0031)$ agitar cubo tátil $(\mathrm{p}=0,017)$ e retirar as mãos do cubo tátil $(\mathrm{p}=0,006)$. 
Figura 3. Média do tempo total de permanência com cada cubo pelas crianças com e sem baixa visão. Uberaba, 2019.

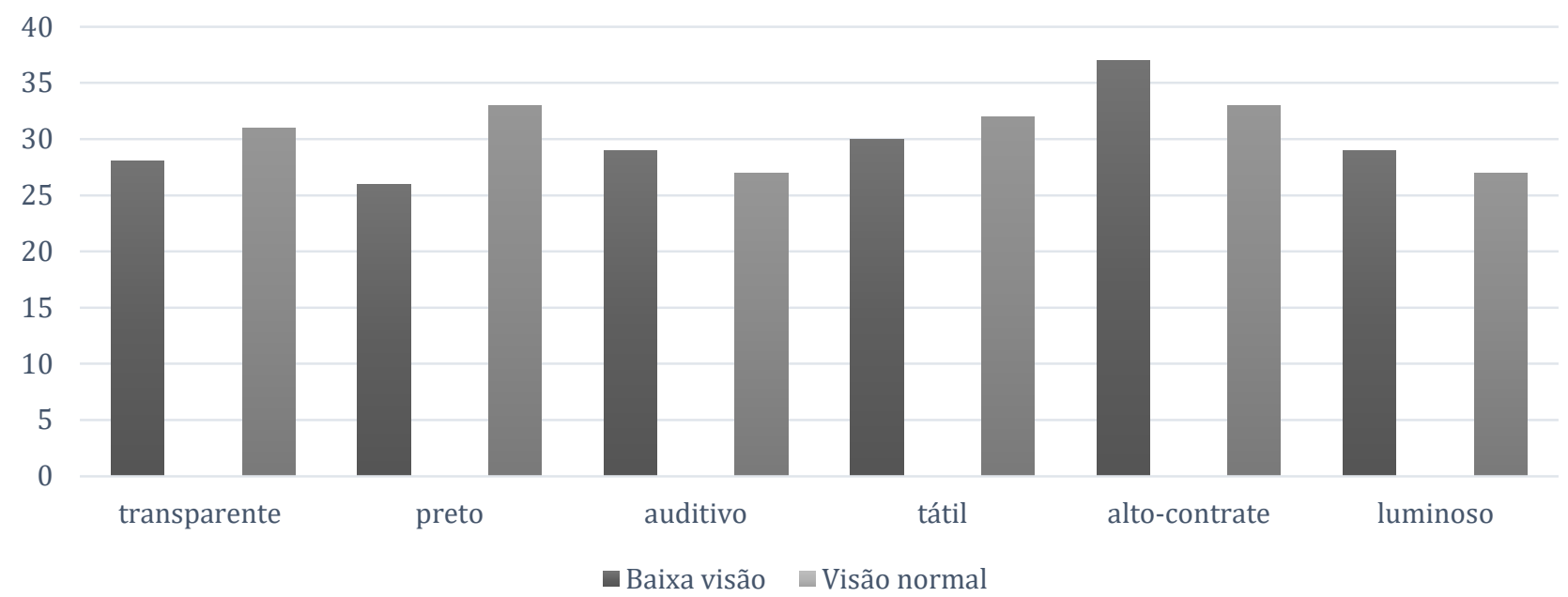

\section{DISCUSSÃO}

Constatou-se que a ausência de diferença entre os dois grupos, em relação à média geral da frequência das ações manipulativas em cada cubo, é um fator positivo para as crianças com baixa visão mostrando, dentro de suas condições e adaptações, apresentaram condições para realizar atividades como as crianças de visão normal ${ }^{3,21}$.

Porém ao verificar a frequência de cada ação manipulativa nos cubos, observa-se diferenças nas ações manipulativas tanto no grupo I como no grupo II. A ação manipulativa girar (cubo luminoso), se destacou no grupo II pelo fato da criança buscar novas informações em relação ao objeto em questão e as luzes presentes contribui para despertar interesse maior sobre o objeto, ocasionando maior repetições em relação ao manuseio.

Em relação ao grupo I as ações manipulativas em destaque agitar (cubo alto-contraste e cubo tátil), foram semelhantes a um estudo já realizado, no qual verificou-se que o estimulo de alto-contraste estimulou as crianças com baixa visão de 3 anos de idade a realizarem maior número de ações motoras ${ }^{3}$. A criança apresenta maior sensibilidade para o contraste, discriminando cores neutras e análogas ${ }^{9}$. 0 alto contraste apresenta cores fortes e com contornos bem definidos o que facilita o reconhecimento do objeto ${ }^{3}$. Neste mesmo estudo não foi observado tal achado para o cubo tátil, o que se infere que as crianças com baixa visão, entre 7 e 10 anos foram mais estimuladas pelas diferentes texturas, gerando mais repetições das ações de agitar.

A criança utiliza a exploração manual para obter maiores informações sobre um determinado objeto, permitindo percepções como o formato, peso, textura e a iniciativa de realizar ações manipulativas, como bater, girar, deslizar, retirando o maior número possível de detalhes ${ }^{15}$. Assim, as crianças com baixa visão do presente estudo realizaram mais a ação de girar os cubos de alto contraste e tátil em relação as crianças sem baixa visão, com o intuito de descobrir os diversos tipos de estímulos apresentados no formato do cubo (seis lados). 0 estimulo de alto-contraste tem como característica contornos e formas bem definidas que despertam o interesse das crianças no objeto, resultante em maior número de ações motoras ${ }^{16}$.

O estímulo tátil também se destacou, fato esse que pode ser justificado pela faixa etária, 7 a 10 anos, e pelos diferentes tipos de texturas apresentadas no cubo, estimulando novos interesses sensoriais. Outro estudo analisou como as crianças com deficiência visual com 3 anos de idade aprendem a usar o sistema sensorial tátil, e mostrou que a exploração tátil estava mais presente quando se apresentava diferentes texturas ${ }^{17}$.

Esse estimulo auxilia a reconhecer sensações (únicas para cada indivíduo) e concretizar na mente a consciência do que realmente estão tocando ${ }^{18}$. A criança de baixa visão, na 
exploração dos objetos, realiza um ato de reorganização, utilizando além da visão residual o sentido tátil, percebendo com melhor eficácia o objeto em questão ${ }^{13}$. 0 cubo tátil apresenta diferentes texturas, o que desperta na criança maior interesse na busca de informações, utilizando todos os seus sentidos sensoriais de maneira integrada na busca de novas descobertas e que vão enriquecer suas experiências com o meio e contribuir para o aperfeiçoamento e aquisição de novas ações manipulativas.

0 fato de não haver um resultado relevante na análise da média de tempo de permanência de cada cubo em segundos pelas crianças corrobora a afirmação realizada na observação da frequência geral das ações manipulativas.

Perante a análise da Tabela 1, Figura 2 e Figura 3, percebe-se que as crianças de baixa visão apresentam um resultado efetivo quando comparadas com crianças de visão normal ao manusear cubos com diferentes estímulos. Essa percepção corrobora um estudo ${ }^{3}$ no qual as crianças com comprometimento visual severo apresentam desempenho semelhante quando comparadas às crianças de visão normal na exploração dos cubos e que a baixa visão não deve ser considerada um fator limitante para as crianças.

0 manuseio dos objetos, que pode ser realizado pelo ato de brincar, contribui para o desenvolvimento da criança, possibilitando novas descobertas. Uma vez que o ato de brincar possibilita a crianças, de maneira singular, a usar a criatividade e personalidade integral descobrindo dessa forma seu potencial ${ }^{9}$.

Crianças com alguma anormalidade no sistema visual devem ser estimuladas precocemente. Para isso, o diagnóstico precoce e a intervenção devem ocorrer o quanto antes, buscando diminuir os impactos negativos gerados na criança. A intervenção é um processo multidisciplinar, que envolve médicos, terapeutas e a família, todos com papeis de suma relevância nesse processo ${ }^{19}$. A criança com deficiência visual podem não apresentar motivação para explorar o meio que a cerca, assim seu desenvolvimento motor, as ações motoras e a sua independência podem ser prejudicados ${ }^{20}$.

A criança está inserida em um meio repleto de sensações que desencadeiam uma cascata de respostas, e a criança com baixa visão necessita de estímulos mais direcionados para que possa ter maiores oportunidades de desenvolvimento com resultados produtivos. Dessa forma, a criação de brinquedos e brincadeiras ou atividades lúdicas envolvendo estímulos sensoriais corretos irão gerar resultados positivos no desenvolvimento das crianças.

\section{CONCLUSÃO}

A maior frequência das ações manipulativas com cada cubo, durante o ato de brincar, pelas crianças de baixa visão de 7 a 10 anos de idade ocorreu nos cubos alto contraste e de textura. 0 tempo de permanência com cada cubo foi semelhante entre os grupos I e II, ressaltando que as crianças com baixa visão apresentam capacidade de interação com os objetos semelhantes as crianças típicas.

Este estudo teve como limitação a dificuldade de realizar coleta de dados em instituições de assistência a pessoas com deficiência visual fora da cidade de início do estudo pela falta de recursos financeiros.

Apesar disto, esta pesquisa pode contribuir de forma positiva para a prática, sobretudo na estimulação e na intervenção de crianças com baixa visão, atentando para o uso adequado de objetos que auxilie nas necessidades particulares dessas crianças tornando o desenvolvimento motor mais dinâmico. Que possa despertar o interesse de pesquisadores para realizar novas pesquisas sobre o tema, disponibilizando cada vez mais recursos eficazes para público em questão. 


\section{REFERÊNCIAS}

1. Cordazzo STD, Vieira ML. Caracterização de brincadeiras de crianças em idade escolar. Psicol Reflex Crit. [Internet]. 2008 [citado em 20 jan 2019]; 21(3):365-73. Disponível em: https://www.scielo.br/scielo.php?script=sci_abstract\&pid=S0102-

79722008000300004\&lng=en\&nrm=iso\&tlng=pt

2. Maluf ACM. Tipos de brincadeiras e como ajudar a criança brincar. In: Maluf ACM. Brincar: prazer e aprendizado [Internet]. Petrópolis, RJ: Vozes; 2003 [citado em 25 fev 2019]. Disponível em: http://www.profala.com/arteducesp64.htm

3. Schmitt BD, Pereira K. Frequência de ações motoras em crianças com baixa visão e visão normal ao explorar cubos com e sem estímulos visuais. Rev Bras Educ Esp. [Internet]. 2016 [citado em 26 jan 2019]; 22(3):399-412. Disponível em: https://www.scielo.br/pdf/rbee/v22n3/1413-6538-rbee-22-03-0399.pdf

4. Carvalho, RP. A influência da postura corporal no movimento de alcance manual em lactentes aos 4 meses de vida [Internet]. [dissertação]. São Carlos, SP: Universidade Federal de São Carlos; 2004 [citado em 28 mar 2019]. Disponível em: https://repositorio.ufscar.br/bitstream/handle/ufscar/5231/DissRPC.pdf?sequence=1\&isAll owed=y

5. Andrade ASS, Barbosa CC, Bessa SL. Anais do Congresso de Iniciação Científica, Estágio e Docência do Campus Formosa: prática pedagógica e a formação docente: teoria e realidade [Internet]. Formosa, GO: Universidade Estadual de Goiás; 2017 [citado em 29 abr 2019]. Disponível em: https://www.anais.ueg.br/index.php/ciced/issue/view/284

6. Lage JB, Nascentes GAN, Pereira K. Influência dos estímulos ambientais domiciliares na mobilidade de crianças com baixa visão: habilidade funcional e assistência do cuidador. Rev Bras Oftalmol. [Internet]. 2016 [citado em 4 fev 2019]; 75(4):290-5. Disponível em: https://www.scielo.br/pdf/rbof/v75n4/0034-7280-rbof-75-04-0290.pdf

7. Azevedo TLR, Gabriela A, Bataliotti SE, Lourenço GF. Uso da audiodescrição no brincar de uma criança com Down na educação infantil. Rev Educ Esp. [Internet]. 2019 [citado em 7 jun 2019]; 32:7. Disponível em: https://periodicos.ufsm.br/educacaoespecial/article/view/23667/pdf

8. Carraro A, Heidrich RO. Brinquedo para estimulação precoce de crianças com deficiência visual [Internet]. [monografia]. Novo Hamburgo, RS: Universidade Feevale; 2010 [citado em 3 mar 2019].

Disponível

em: https://biblioteca.feevale.br/Monografia/MonografiaAndressaCarraro.pdf

9. Silva RS, Silva RP. Estudo sobre o desenvolvimento do projeto de brinquedos: enfoque na criança com deficiência visual. Educ Gráf. [Internet]. 2018 [citado em 6 mar 2019]; 22(2):30718. Disponível em: http://www.educacaografica.inf.br/wp-content/uploads/2018/11/21_0DESENVOLVIMENTO-DO-PROJETO_307-318.pdf

10. Ministério da Saúde (Br). Secretaria de Atenção à Saúde. Diretrizes de atenção à saúde ocular na infância: detecção e intervenção precoce para a prevenção de deficiências visuais [Internet]. Brasília, DF: Ministério da Saúde; 2013 [citado em 3 jun 2019]. Disponível em: http://bvsms.saude.gov.br/bvs/publicacoes/diretrizes_atencao_saude_ocular_infancia.pdf 11. Couto JÁ, Oliveira LAG. As principais causas de cegueira e baixa visão em escola para deficientes visuais. Rev Bras Oftalmol. [Internet]. 2016 [citado em 25 fev 2019]; 75(1):26-9. Disponível em: https://www.scielo.br/pdf/rbof/v75n1/0034-7280-rbof-75-01-0026.pdf 12. Graziano RM, Leone CR. Problemas oftalmológicos mais frequentes e desenvolvimento visual do pré-termo extremo. J Pediatr. (Rio J.). [Internet]. 2005 [citado em 11 abr 2019]; 81(1 Supl 1):S95-S100. Disponível em: https://www.scielo.br/pdf/jped/v81n1s1/v81n1s1a12.pdf 13. Schmitt, BD, Pereira K. Caracterização das ações motoras de crianças com baixa visão e visão normal durante o brincar: cubos com e sem estímulo luminoso ou alto contraste. Rev Bras Educ Espec. [Internet]. 2014 [citado em 15 abr 2019]; 20(3):435-48. Disponível em: 
https://www.scielo.br/pdf/rbee/v20n3/08.pdf. DOI: https://doi.org/10.1590/S141365382014000300009

14. Oliveira C, Silva QPN, Pelizaro BP, Pereira K. Ações manipulativas e o ato de criar brincadeiras com cubos em crianças com e sem baixa visão. Rev Saúde Desenvolv Hum. [Internet]. 2020 [citado em 1 maio 2020]; 8(1):49-58. Disponível em: https://revistas.unilasalle.edu.br/index.php/saude_desenvolvimento/article/view/6038/pdf 15. Soska KC, Adolf KE, Johnson SP. Systems in development: motor skill acquisition facilitates 3D object completion. Dev Psychol. [Internet]. 2010 [citado em 14 fev 2019]; 46:129-38. Disponível em: https://www.ncbi.nlm.nih.gov/pmc/articles/PMC2805173/

16. Delgado IMC, Pereira LM. Characterization of functional vision in preschool children with low vision: the identification of pedagogical strategies. Int Congr Ser. [Internet]. 2005 [citado em 3 abr 2019]; 1282:93-6. Disponível https://www.sciencedirect.com/science/article/abs/pii/S0531513105007521?via\%3Dihub 17. Smitsman AW; Schellinerhout R. Exploratory behavior in blind infants: how to improve touch? Infant Behav Dev. [Internet]. 2000 [citado em 11 jan 2019]; 23(3):485-511. Disponível em:

https://www.researchgate.net/publication/223670838_Exploratory_behavior_in_blind_infan ts_How_to_improve_touch

18. Dondis DA. Sintaxe da linguagem visual [Internet]. Tradução Camargo JL. 3ed. São Paulo: Martins Fontes; 2015 [citado em 15 jan 2019]. 248p. Disponível em: http://www3.uma.pt/dmfe/DONDIS_Sintaxe_da_Linguagem_Visual.pdf

19. Gagliardo HGRG, Nobre MIRS. Intervenção precoce na criança com baixa visão. Rev Neurociênc. [Internet]. 2001 [citado em 22 fev 2019]; 9(1):16-9. Disponível em: https://www.researchgate.net/publication/339613796_Intervencao_Precoce_na_Crianca_co m_Baixa_Visao

20. Lagel JB, Nascentes GAN, Pereira K. Influência dos estímulos ambientais domiciliares na mobilidade de crianças com baixa visão: habilidade funcional e assistência do cuidador. Rev Bras Oftalmol. [Internet]. 2016 [citado em 20 abr 2019]; 75(4):290-5. Disponível em: https://www.scielo.br/pdf/rbof/v75n4/0034-7280-rbof-75-04-0290.pdf. DOI 10.5935/00347280.20160058

21. Schmitt BD. Ações motoras de crianças com baixa visão durante o brincar: cubos com e sem estímulo visual [Internet]. [dissertação]. Uberaba, MG: Universidade Federal do Triângulo Mineiro; 2014 [citado em 25 abr 2019]. 65p. Disponível em: http://bdtd.uftm.edu.br/bitstream/tede/193/5/Dissert\%20Beatriz\%20D\%20Schmitt.pdf

22. Borges AAP, Campos RHF. A Escolarização de alunos com deficiência em Minas Gerais: das classes especiais à educação inclusiva. Rev Bras Educ Espec. [Internet]. 2018 [citado em 7 mar 2019]; 24:69-84. Disponível em: https://doi.org/10.1590/s1413-65382418000400006

23. Cordazzo STD, Vieira ML. Caracterização de brincadeiras de crianças em idade escolar. Psicol Reflex Crit. [Internet]. 2008 [citado em 11 maio 2019]; 21(3):365-73. DOI: https://doi.org/10.1590/S0102-79722008000300004

24. Bakke HA. Adaptação e validação do MABC-2 para crianças com baixa visão [Internet]. [tese]. Recife: Universidade Federal de Pernambuco; 2015 [citado em 26 maio 2019]. 122f. Disponível em: https://repositorio.ufpe.br/handle/123456789/15053

25. Motta MP, Marchiore LM, Pinto JH. Confecção de brinquedo adaptado: uma proposta de intervenção da terapia ocupacional com crianças de baixa visão. Mundo Saúde [Internet]. 2008 [citado em 28 mar 2019]; 32(2):139-45. Disponível em: http://www.saocamilosp.br/pdf/mundo_saude/59/139a145.pdf

26. Santos MCS. Escala de Desenvolvimento Motor: adaptação para crianças com baixa visão dos 07 aos 10 anos de idade [Internet]. [dissertação]. Uberaba, MG: Universidade Federal do Triângulo Mineiro; 2018 [citado em 14 mar 2019]. 114f. Disponível em: http://bdtd.uftm.edu.br/handle/tede/587 
27. Ulrich DA. The Test of Gross Motor Development [Internet]. $2^{\text {nd }}$. Austin, Texas: ProdEd; 2000 [citado em 26 maio 2019]. 8p. Disponível em: https://www.pgsd.org/cms/lib07/PA01916597/Centricity/Domain/380/TGMD2\%20Assessmt.pdf

Editora Associada: Vania Del Arco Paschoal

\section{CONTRIBUIÇÕES}

Caroline de Oliveira colaborou na concepção e obtenção dos dados. Karine Pereira contribuiu na concepção, redação e revisão. Nathalia Quintino atuou na concepção, obtenção dos dados e análise, redação e revisão. Paula Berteli Pelizaro atuou na revisão.

\section{Como citar este artigo (Vancouver)}

Silva NQP, Oliveira C, Pelizaro PB, Pereira K. Frequência e duração das ações manipulativas no ato de brincar com cubos em crianças com baixa visão. REFACS [Internet]. 2021 [citado em inserir dia, mês e ano de acesso]; 9(Supl. 1):300-311. Disponível em: inserir link de acesso. DOI: inserir link do DOI

\section{Como citar este artigo (ABNT)}

SILVA, N. Q. P.; OLIVEIRA, C.; PELIZARO, P. B.; PEREIRA, K. Frequência e duração das ações manipulativas no ato de brincar com cubos em crianças com baixa visão. REFACS, Uberaba, MG, v. 9, p. 300-311, 2021. Supl. 1. DOI: inserir link do DOI. Disponível em: inserir link de acesso. Acesso em: inserir dia, mês e ano de acesso.

\section{Como citar este artigo (APA)}

Silva, N.Q.P., Oliveira, C., Pelizaro, P.B. \& Pereira, K. (2021). Frequência e duração das ações manipulativas no ato de brincar com cubos em crianças com baixa visão. REFACS, 9(Supl. 1), 300-311. Recuperado em inserir dia, mês e ano de acesso de inserir link de acesso. DOI: inserir link do DOI. 